\title{
INTERVENSI PSIKOEDUKASI DALAM MENGATASI STIGMA DAN HAMBATAN KOMUNIKASI PADA TEMAN TULI YANG TERGABUNG DALAM GERKATIN KEPEMUDAAN
}

\section{Grace Sutrisnadipraja ${ }^{1,}$ Nathasya Shesilia K. ${ }^{1}$, Sheila Putri F. ${ }^{1}$, Yessica Yulianto ${ }^{1}$, Penny Handayani $^{2}$, Weny Pandia Sembiring ${ }^{2}$}

\author{
${ }^{1}$ Mahasiswa Magister Studi Profesi Psikologi, Universitas Katolik Atma Jaya, Jakarta \\ Email: sutrisnadipraja.clara@gmail.com \\ nathasyask13@gmail.com \\ spfajrianti@gmail.com \\ yeyeonlehh@gmail.com \\ ${ }^{2}$ Fakultas Psikologi, Universitas Katolik Atma Jaya, Jakarta \\ Email: penny.handayani@atmajaya.ac.id \\ Weny_pandia@yahoo.com
}

\begin{abstract}
ABSTRAK
Semua individu berhak untuk memperoleh kesempatan yang sama dalam berbagai aspek kehidupan. Namun, perolehan hak yang sama tidak selalu terjadi pada individu-individu yang mengalami disabilitas, termasuk individu dengan disabilitas tuna rungu atau yang dikenal dengan sebutan "Teman Tuli". Salah satu organisasi khusus yang dibentuk untuk mewadahi Teman Tuli muda dan anak-anak tuli di Indonesia adalah Gerkatin Kepemudaan (Gerakan untuk Kesejahteraan Tuli Indonesia). Tujuan dibentuknya Gerkatin Kepemudaan ini adalah agar muda-mudi bisa lebih percaya diri, mandiri, dan setara dengan orang dengar, serta memperkuat kapasitas anak muda tuli untuk menghasilkan pemimpin, baik untuk masyarakat tuli ataupun masyarakat Indonesia. Pada saat ini, Teman Tuli di Indonesia menggunakan Bahasa Isyarat Indonesia (BISINDO) untuk berkomunikasi. Bahasa isyarat adalah bahasa yang menggunakan gerakan tangan, kepala, tubuh dan sebagainya, terutama diciptakan oleh orang tuli dan untuk orang tuli (kadang-kadang untuk pendengar). Namun pada saat ini jumlah Teman Dengar yang dapat memahami BISINDO masih sangat minim karena kurangnya sosialisasi BISINDO kepada masyarakat luas. Teman Tuli yang jumlahnya terbilang tidak sedikit ini masih harus menghadapi stigma dari masyarakat luas, dan di saat yang sama juga mengalami kesulitan dalam kehidupan sehari-hari karena kurangnya fasilitas, sarana, dan prasarana yang mendukung. Tujuan dilakukannya intervensi untuk mewujudkan masyarakat yang lebih inklusif terhadap Teman Tuli, meminilasir stigma terhadap Teman Tuli oleh para Teman Dengar yang cenderung negatif, dan membuka aksesbilitas komunikasi dengan Teman Tuli melalui Bahasa Isyarat Indonesia (BISINDO).
\end{abstract}

Kata Kunci: Psikoedukasi, Hambatan Komunikasi, Stigma, Teman Tuli, Gerkatin.

\section{PENDAHULUAN}

Semua individu berhak untuk memperoleh kesempatan yang sama dalam berbagai aspek kehidupan. Hal ini tercantum dalam Undang-Undang No. 39 Tahun 1999 tentang Hak Asasi Manusia (HAM). Namun, perolehan hak yang sama tidak selalu terjadi pada individu-individu yang mengalami disabilitas, termasuk individu dengan disabilitas tuna rungu atau yang dikenal dengan sebutan "Teman Tuli" (Tuwo, 2016). Teman Tuli adalah istilah yang dipilih oleh tuna rungu di Indonesia sebagai identitas diri mereka. Mereka lebih senang dipanggil Teman Tuli karena menurut mereka istilah tuna rungu dipersepsikan sebagai sebuah kecacatan atau penyakit yang biasanya digunakan dalam istilah medis/kedokteran. Memanggil para Teman Tuli dengan sebutan tuna rungu membuat mereka merasa dianggap sakit. Kemudian, Teman Tuli menggunakan istilah "Teman Dengar" bagi individu yang tidak memiliki gangguan pendengaran (non-difabel).

Berdasarkan data Susenas tahun 2012 silam, di Indonesia ada sekitar 7,87\% individu yang mengalami disabilitas pendengaran (Kementerian Kesehatan RI, 2014). Secara spesifik di provinsi 
DKI Jakarta, terdapat 57.307 jiwa yang mengalami gangguan pendengaran ringan dan 8.607 jiwa yang mengalami gangguan pendengaran berat (Kementerian Kesehatan RI, 2014). Berdasarkan survei Susenas (2012) dapat diketahui bahwa jumlah persentase Teman Tuli di Indonesia tidaklah sedikit. Namun nyatanya aksesibilitas untuk penyandang disabilitas khususnya Teman Tuli belum dapat dikatakan memadai. Penyandang disabilitas secara umum masih cukup sulit untuk mengakses pendidikan terutama pendidikan tinggi di Universitas (Afrianty, 2015; Afrianty \& Soldatic, 2016). Selain dalam sektor pendidikan, Teman Tuli juga kerap mengalami kesulitan dalam akses kesehatan (De Souza et al., 2017). Hasil penelitian di India (dalam Kusters, 2017) juga menunjukkan bahwa masih banyak kesulitan yang dijumpai para individu tuli terkait penggunaan kendaraan publik, misalnya tidak tersedianya pemberitahuan yang dapat diakses individu tuli. Selain fasilitas fisik, masyarakat (Teman Dengar pada umumnya) juga memberikan stigma yang tidak baik bagi Teman Tuli.

Teman Tuli dapat diklasifikasikan ke dalam empat jenis berdasarkan tingkat keparahan gangguan yang dimiliki, antara lain (Lutf, 2000): 1) Moderate hearing loss (41-44 desiBel), yaitu individu membutuhkan alat bantu dengar namun dapat memahami percakapan pada tiga sampai lima kaki; 2) Moderately severe hearing loss (56-70 desiBel), yaitu individu membutuhkan bahasa dan terapi wicara serta suara pembicaraan harus cukup keras agar individu dapat memahami pembicaraan; 3) Severe hearing loss (70-90 desiBel), yaitu individu membutuhkan pendidikan khusus, dapat mengidentifikasi suara bising di lingkungan sekitar, serta dapat membedakan vokal namun tidak dapat membedakan konsonan; 4) Profound hearing loss (91+ desiBel), yaitu individu membutuhkan kelas khusus dalam pendidikan, dapat mendengar beberapa suara keras, dan tidak dapat bergantung pada indera pendengaran sebagai alat utama untuk berkomunikasi.

Gerkatin Kepemudaan (Gerakan untuk Kesejahteraan Tuli Indonesia) adalah salah satu organisasi khusus yang dibentuk untuk mewadahi Teman Tuli muda dan anak-anak tuli di Indonesia. Tujuan dibentuknya Gerkatin Kepemudaan ini adalah agar muda-mudi bisa lebih percaya diri, mandiri, dan setara dengan orang dengar, serta memperkuat kapasitas anak muda tuli untuk menghasilkan pemimpin, baik untuk masyarakat tuli ataupun masyarakat Indonesia.

Pada saat ini, Teman Tuli di Indonesia menggunakan Bahasa Isyarat Indonesia (BISINDO) untuk berkomunikasi. Bahasa isyarat adalah bahasa yang menggunakan gerakan tangan, kepala, tubuh dan sebagainya, terutama diciptakan oleh orang tuli dan untuk orang tuli (kadang-kadang untuk pendengar). Namun pada saat ini jumlah Teman Dengar yang dapat memahami BISINDO masih sangat minim karena kurangnya sosialisasi BISINDO kepada masyarakat luas (soldier.id, 2018).

Teman Tuli yang jumlahnya terbilang tidak sedikit ini masih harus menghadapi stigma dari masyarakat luas, dan di saat yang sama juga mengalami kesulitan dalam kehidupan sehari-hari karena kurangnya fasilitas, sarana, dan prasarana yang mendukung.

Tujuan dilakukannya intervensi untuk mewujudkan masyarakat yang lebih inklusif terhadap Teman Tuli, meminilasir stigma terhadap Teman Tuli oleh para Teman Dengar yang cenderung negatif, dan membuka aksesbilitas komunikasi dengan Teman Tuli melalui Bahasa Isyarat Indonesia(BISINDO).

\section{METODE PELAKSANAAN}

Pelaksanaan intervensi diawali dengan registrasi dan pembukaan, lalu pengisian pre-test untuk para peserta Teman Dengar, setelah itu masing-masing Teman Dengar akan dipasangkan dengan Teman Tuli, tanpa tahu bahwa lawan bicaranya adalah tunarungu dan diminta mengobrol satu sama lain, lalu dilanjutkan dengan pemberian materi BISINDO kepada seluruh peserta Teman 
Tuli dan Teman Dengar yang diberikan oleh pemateri dari salah satu Teman Tuli dan penerjemahnya. Setelah pemberian materi BISINDO dilanjutkan dengan praktik langsung berbincang-bincang dengan pasangan Teman Dengar dan Teman Tuli yang sudah dipasangkan sebelum pemberian materi dan diakhiri dengan pengisian post-test untuk para peserta Teman Dengar dan penutupan.

Metode observasi digunakan juga dalam proses pelaksanaan intervensi dengan tujuan untuk mengetahui intervensi yang diberikan sudah berjalan secara efektif atau belum. Poin-poin yang diobservasi adalah 1) Penguasaan partisipan terhadap alfabet (A-Z) BISINDO, dan 2) perubahan durasi dalam mengkomunikasikan 12 butir pertanyaan yang diberikan.

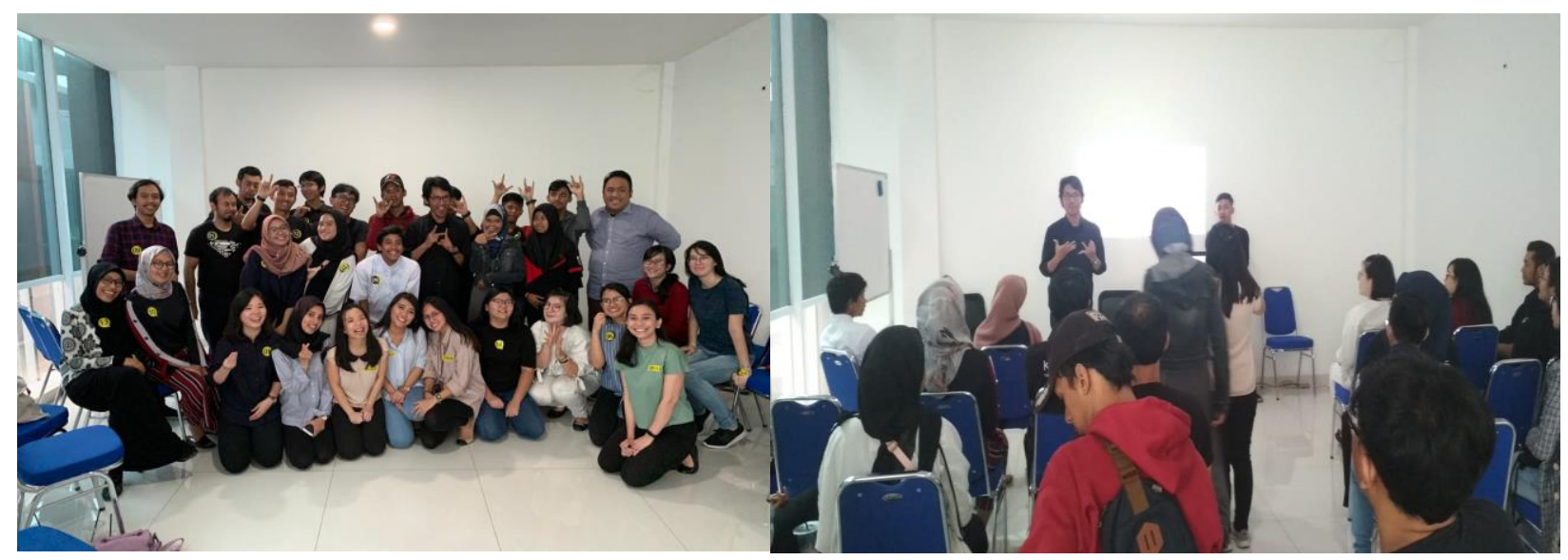

Gambar $1 \& 2$ Para Peserta Teman Dengar dan Teman Tuli yang berpartisipasi dalam Intervensi

\section{HASIL DAN PEMBAHASAN}

Berikut adalah rundown program intervensi untuk dijalankan:

Tabel 1. Rundown Acara

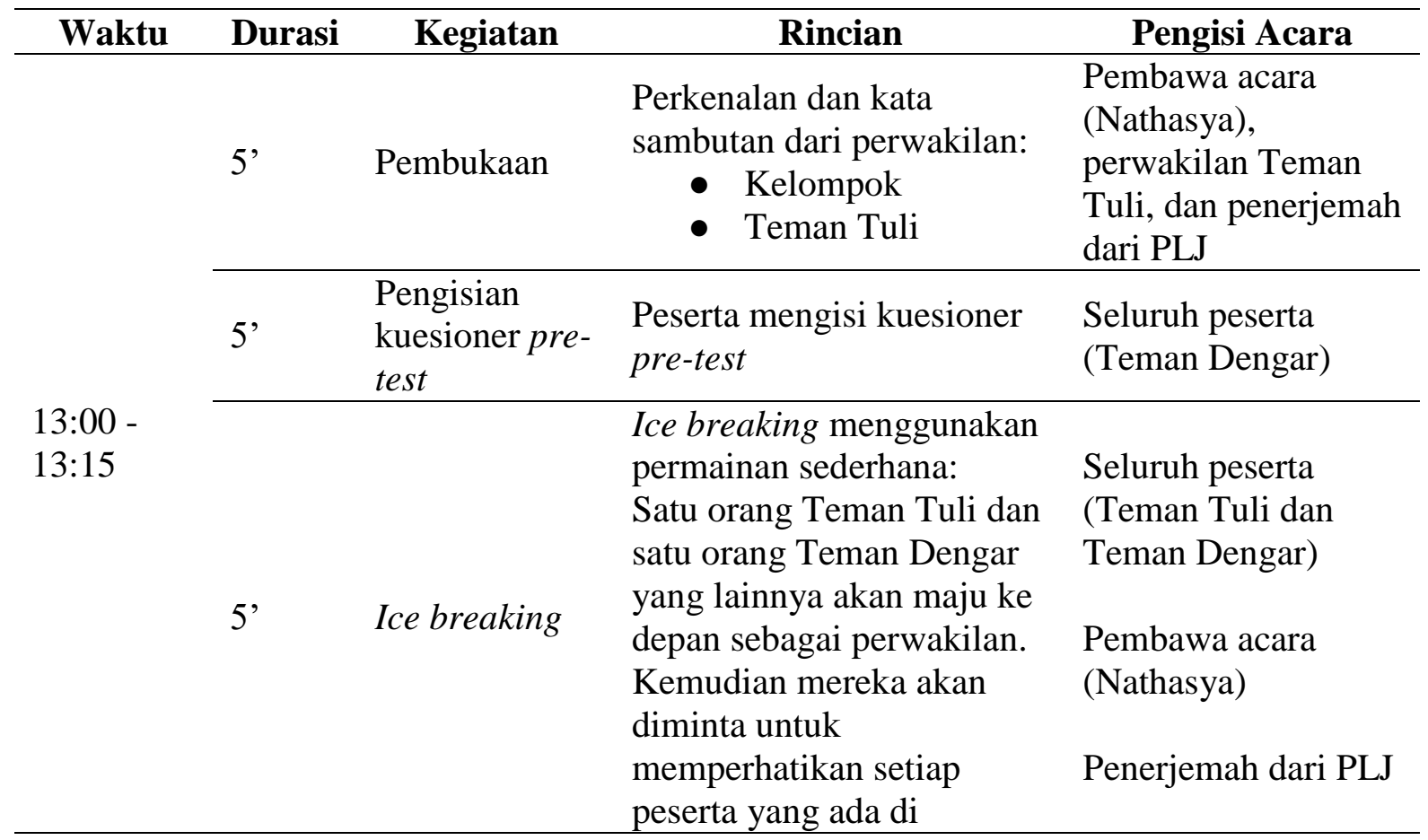




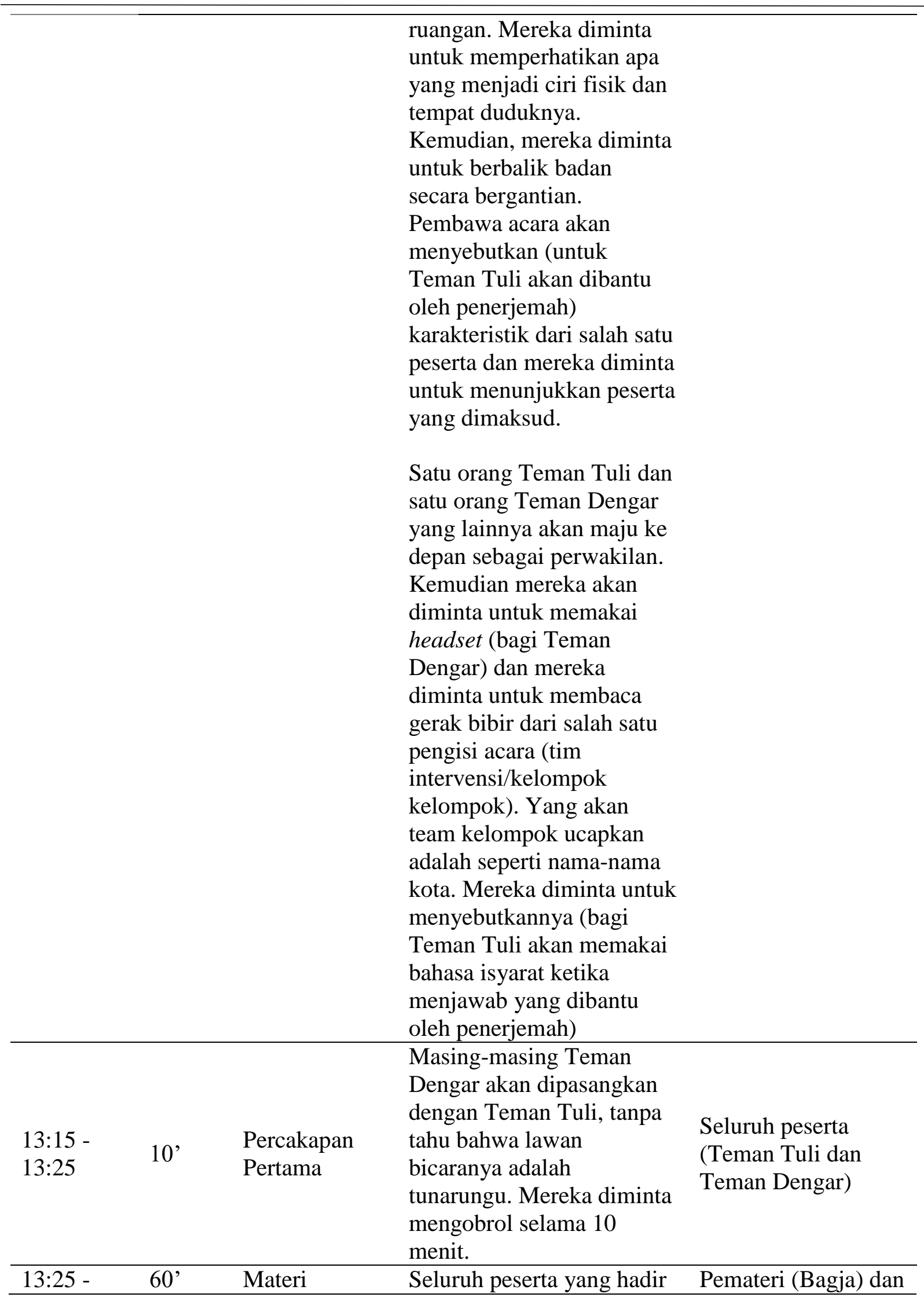




\begin{tabular}{|c|c|c|c|c|}
\hline $14: 25$ & & BISINDO & $\begin{array}{l}\text { diberikan materi mengenai } \\
\text { bahasa isyarat Indonesia. }\end{array}$ & penerjemah dari PLJ \\
\hline $\begin{array}{l}14: 25- \\
14: 35\end{array}$ & $10^{\prime}$ & $\begin{array}{l}\text { Percakapan } \\
\text { Kedua }\end{array}$ & $\begin{array}{l}\text { Masing-masing peserta } \\
\text { intervensi akan } \\
\text { dipasangkan dengan } \\
\text { Teman Tuli yang berbeda } \\
\text { dari sesi percakapan } \\
\text { pertama. Kali ini, peserta } \\
\text { akan mengobrol dengan } \\
\text { menggunakan } \\
\text { pengetahuannya tentang } \\
\text { BISINDO. }\end{array}$ & $\begin{array}{l}\text { Seluruh peserta } \\
\text { (Teman Tuli dan } \\
\text { Teman Dengar) }\end{array}$ \\
\hline $\begin{array}{l}14: 35- \\
14: 50\end{array}$ & $15^{\prime}$ & Debriefing & $\begin{array}{l}\text { Masing-masing peserta } \\
\text { intervensi menceritakan } \\
\text { sedikit tentang bagaimana } \\
\text { pandangan mereka } \\
\text { mengenai Teman Tuli dan } \\
\text { perubahan apa yang } \\
\text { mereka rasakan setelah } \\
\text { mulai memahami } \\
\text { BISINDO dan etika. }\end{array}$ & $\begin{array}{l}\text { Pembawa acara } \\
\text { (Sheila) } \\
\text { 3-4 orang peserta } \\
\text { (Teman Dengar) } \\
\text { Penerjemah dari PLJ }\end{array}$ \\
\hline \multirow{3}{*}{$\begin{array}{l}14: 50- \\
15: 00\end{array}$} & 5 & $\begin{array}{l}\text { Pengisian } \\
\text { kuesioner } \\
\text { post-test }\end{array}$ & $\begin{array}{l}\text { Masing-masing peserta } \\
\text { Teman Dengar diminta } \\
\text { mengisi kuesioner post-test }\end{array}$ & $\begin{array}{l}\text { Seluruh peserta } \\
\text { (Teman Dengar) }\end{array}$ \\
\hline & \multirow[t]{2}{*}{5} & \multirow[t]{2}{*}{ Penutupan } & $\begin{array}{l}\text { Penutupan acara dari: } \\
\text { - Kelompok } \\
\text { - Teman Tuli } \\
\text { Foto bersama }\end{array}$ & $\begin{array}{l}\text { Pembawa acara } \\
\text { (Sheila) } \\
\text { Perwakilan Teman } \\
\text { Tuli }\end{array}$ \\
\hline & & & Pembagian konsumsi & Penerjemah dari PLJ \\
\hline
\end{tabular}

Rata-rata Teman Dengar yang hadir sebagai partisipan di program intervensi ini berusia 20-29 tahun. Sebanyak 11 partisipan berjenis kelamin perempuan, dan tiga partisipan lainnya berjenis kelamin laki-laki. Sebanyak enam orang partisipan merupakan pegawai swasta di berbagai sektor industri. Terdapat pula seorang partisipan yang merupakan seorang tenaga profesional, yaitu dokter. Selain pegawai swasta dan profesional, partisipan lainnya berstatus pegawai lepas (freelancer) atau mahasiswa. Berdasarkan hasil wawancara terhadap Teman Dengar yang terpapar Teman Tuli dan yang tidak terpapar Teman Tuli diketahui bahwa Teman Dengar yang tidak terpapar memiliki stigma yang buruk terhadap Teman Tuli, oleh karena itu kelompok berupaya untuk mengundang partisipan yang tidak terpapar oleh Teman Tuli karena salah satu tujuan intervensi ini adalah untuk meminimalisir stigma yang ada. 


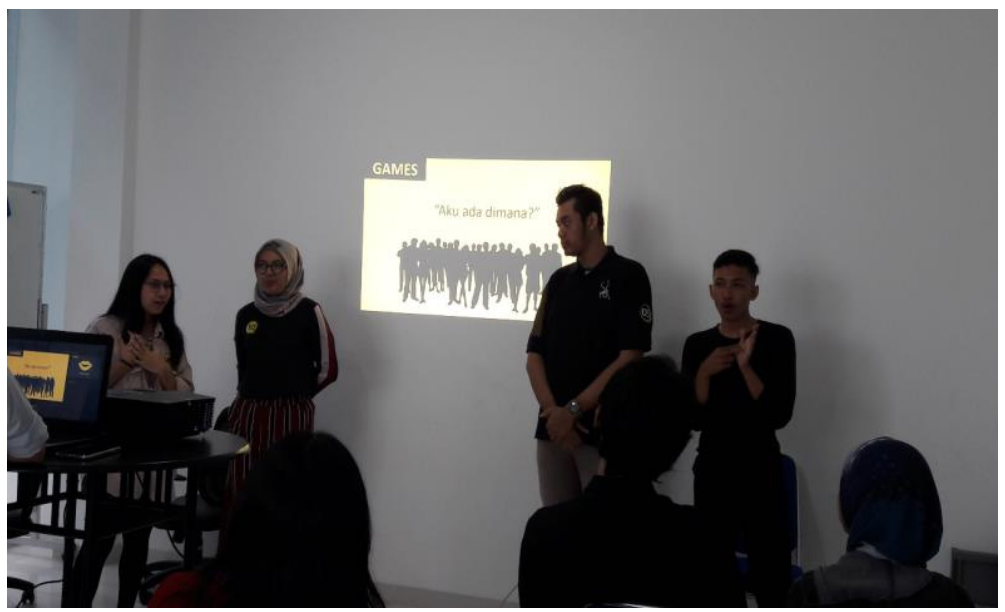

Gambar 3. Pemateri dan Penerjemah dari PLJ memberikan materi BISINDO

Berdasarkan hasil pre-test dan post-test yang diberikan terkait karakteristik Teman Tuli menurut Teman Dengar, diketahui bahwa seluruh partisipan (Teman Dengar) mengalami perubahan yang signifikan terhadap cara pandang atau persepsi mereka terhadap karakteristik Teman Tuli. Karakteristik pada pre-test yang semula digambarkan dalam sifat negatif telah berubah menjadi karakteristik yang lebih positif pada hasil post-test setiap partisipan. Peningkatan gambaran karakteristik positif ini bervariasi, mulai dari satu hingga tiga karakteristik positif. Di setiap terjadi peningkatan pada karakteristik positif maka terjadi penurunan pada karakteristik negatif.

Tabel 2. Hasil Evaluasi Stigma

\begin{tabular}{|c|c|c|c|c|c|c|c|c|}
\hline \multirow{2}{*}{ No. } & \multirow{2}{*}{ Karakteristik } & \multirow{2}{*}{$(+)$} & \multirow{2}{*}{$(-)$} & \multirow{2}{*}{ Karakteristik } & \multirow{2}{*}{$(+)$} & \multirow{2}{*}{$(-)$} & \multicolumn{2}{|c|}{ Perubahan } \\
\hline & & & & & & & $(+)$ & $(-)$ \\
\hline 1 & $\begin{array}{l}\text { Komunikasi aneh }(-), \\
\text { tajam secara visual }(+) \\
\text { ekspresif }(+)\end{array}$ & 2 & 1 & $\begin{array}{l}\text { Unik/ menarik }(+), \\
\text { mau mencoba } \\
\text { memahami Teman } \\
\text { Dengar }(+), \text { sabar }(+)\end{array}$ & 3 & 0 & +1 & -1 \\
\hline 2 & $\begin{array}{l}\text { Komunikasi tidak efektif (-), } \\
\text { harus bicara dengan suara ekstra } \\
\text { keras (-), tidak bisa komunikasi (- } \\
\text { ) }\end{array}$ & 0 & 3 & $\begin{array}{l}\text { Ramah }(+), \text { baik }(+), \\
\text { mau mengajarkan }(+)\end{array}$ & 3 & 0 & +3 & -3 \\
\hline 3 & $\begin{array}{l}\text { Detail }(+) \text {, atentif }(+) \text {, } \\
\text { Terlalu sensitif }(-)\end{array}$ & 2 & 1 & $\begin{array}{l}\text { Bersemangat }(+) \text {, asik } \\
(+) \text {, wawasannya luas } \\
(+)\end{array}$ & 3 & 0 & +1 & -1 \\
\hline 4 & $\begin{array}{l}\text { Ramah }(+), \text { semangat }(+) \\
\text { aneh }(-)\end{array}$ & 2 & 1 & $\begin{array}{l}\text { Ramah }(+), \\
\text { menyenangkan }(+), \\
\text { aktif }(+)\end{array}$ & 3 & 0 & +1 & -1 \\
\hline 5 & $\begin{array}{l}\text { Bisu (-), friendly (+), menutup } \\
\text { diri (-) }\end{array}$ & 1 & 2 & $\begin{array}{l}\text { Sangat ramah }(+), \\
\text { sangat ekspresif }(+), \\
\text { terbuka }(+)\end{array}$ & 3 & 0 & +2 & -2 \\
\hline 6 & $\begin{array}{l}\text { Tidak bisa dengar/kemampuan } \\
\text { mendengar terbatas (-), cara } \\
\text { berkomunikasinya aneh (-), bisa }\end{array}$ & 1 & 2 & $\begin{array}{l}\text { Ramah }(+), \text { sabar }(+), \\
\text { tangguh dalam } \\
\text { menjalani hidup }(+)\end{array}$ & 3 & 0 & +2 & -2 \\
\hline
\end{tabular}


membaca ekspresi wajah lawan

bicara $(+)$

\begin{tabular}{|c|c|c|c|c|c|c|c|c|}
\hline 7 & $\begin{array}{l}\text { Tidak sehat/sakit (-), cara } \\
\text { berkomunikasinya aneh } \\
(-) \text {, pendengarannya terganggu (-) }\end{array}$ & 0 & 3 & $\begin{array}{l}\text { Tangguh }(+), \\
\text { bersemangat }(+), \text { tidak } \\
\text { sombong }(+)\end{array}$ & 3 & 0 & +3 & -3 \\
\hline 8 & $\begin{array}{l}\text { Ada kekurangan }(-) \text {, tenang }(+), \\
\text { bisu (-) }\end{array}$ & 1 & 2 & $\begin{array}{l}\text { Peka dengan } \\
\text { lingkungan }(+), \\
\text { merangkul }(+), \\
\text { bersemangat }(+)\end{array}$ & 3 & 0 & +2 & -2 \\
\hline 9 & $\begin{array}{l}\text { Menarik (+), sensitif }(-) \text {, } \\
\text { memiliki kekurangan }(-)\end{array}$ & 1 & 2 & $\begin{array}{l}\text { Hebat }(+), \text { mau berbagi } \\
(+), \\
\text { masih harus hati-hati } \\
\text { menjaga perilaku }(+)\end{array}$ & 2 & 1 & +1 & -1 \\
\hline 10 & $\begin{array}{l}\text { Kurang peka }(-), \text { egois } \\
(-), \text { kurang perhatian }(-)\end{array}$ & 0 & 3 & $\begin{array}{l}\text { Inspiratif }(+), \text { tidak } \\
\text { takut lagi untuk } \\
\text { berkomunikasi }(+) \\
\text { sensitif }(-)\end{array}$ & 2 & 1 & +2 & -2 \\
\hline 11 & $\begin{array}{l}\text { Tidak mampu mendengar(-), } \\
\text { sulit berbicara (-), } \\
\text { cara berkomunikasinya aneh (-) }\end{array}$ & 0 & 3 & $\begin{array}{l}\text { Bisa berkomunikasi } \\
\text { dengan baik }(+) \text {, seru } \\
(+), \text { wajah dan gesture- } \\
\text { nya ekspresif }(+)\end{array}$ & 3 & 0 & +3 & -3 \\
\hline 12 & $\begin{array}{l}\text { Aneh }(-) \text {, sulit berkomunikasi }(-) \text {, } \\
\text { tidak bisa berbaur (-) }\end{array}$ & 0 & 3 & $\begin{array}{l}\text { Terbuka }(+), \text { friendly } \\
(+), \text { ada yang kurang } \\
\text { atentif } \\
(-)\end{array}$ & 2 & 1 & +2 & -2 \\
\hline 13 & $\begin{array}{l}\text { Tidak mendengar }(-) \text {, susah bicara } \\
(-) \text {, } \\
\text { sensitif }(-)\end{array}$ & 0 & 3 & $\begin{array}{l}\text { Komunikatif }(+) \\
\text { hangat }(+), \text { mau } \\
\text { mengajarkan }(+)\end{array}$ & 3 & 0 & +3 & -3 \\
\hline 14 & $\begin{array}{l}\text { Sulit dipahami }(-) \text {, canggung }(-) \text {, } \\
\text { tidak bisa bicara }(-)\end{array}$ & 0 & 3 & $\begin{array}{l}\text { Aktif bicara }(+), \\
\text { ternyata bisa membaca } \\
\text { gerak bibir }(+) \text {, asik } \\
(+)\end{array}$ & 3 & 0 & +3 & -3 \\
\hline
\end{tabular}

Yang pertama diukur adalah penguasaan masing-masing partisipan terhadap alfabet (AZ) BISINDO. Observasi dilakukan kepada 14 partisipan Teman Dengar (dilakukan oleh tiga anggota kelompok), dengan menggunakan checklist perilaku. Berikut hasil penguasaan alfabet BISINDO para partisipan:

Tabel 3. Hasil Evaluasi Pengetahuan: Abjad BISINDO

\begin{tabular}{|l|l|l|l|l|l|l|l|l|l|l|l|l|l|l|}
\hline No & $\mathbf{1}$ & $\mathbf{2}$ & $\mathbf{3}$ & $\mathbf{4}$ & $\mathbf{5}$ & $\mathbf{6}$ & $\mathbf{7}$ & $\mathbf{8}$ & $\mathbf{9}$ & $\mathbf{1 0}$ & $\mathbf{1 1}$ & $\mathbf{1 2}$ & $\mathbf{1 3}$ & $\mathbf{1 4}$ \\
\hline A & & & & & & & & & & & & & & \\
\hline B & & & & & & & & & & & & & & \\
\hline C & & & & & & & & & & & & & & \\
\hline D & & & & & & & & & & & & & & \\
\hline E & & & & & & & & & & & & & & \\
\hline
\end{tabular}


Hambatan Komunikasi pada Teman Tuli yang Tergabung dalam GERKATIN Kepemudaan

\begin{tabular}{|c|c|c|c|c|c|c|c|c|c|c|c|c|c|c|}
\hline $\mathbf{F}$ & & & $X$ & & & & & & & $X$ & & & & \\
\hline $\mathbf{G}$ & & & $X$ & & & & & & & & & & & \\
\hline $\mathbf{H}$ & & & $\mathrm{X}$ & & & & & $X$ & & & & & & \\
\hline I & & & & & & & & & & & & & & \\
\hline $\mathbf{J}$ & & & & & & & & & & & & & & \\
\hline $\mathbf{K}$ & & & & $X$ & & & & $X$ & & & & & & \\
\hline $\mathbf{L}$ & & & & & & & & & & & & & & \\
\hline $\mathbf{M}$ & & & & & & & & & & & & & & \\
\hline $\mathbf{N}$ & & & & & & & & & & & & & & \\
\hline $\mathbf{O}$ & & & & & & & & & & & & & & \\
\hline $\mathbf{P}$ & & & & & & & & & & & & & & \\
\hline $\mathbf{Q}$ & & & & & & & & & & & & & & \\
\hline $\mathbf{R}$ & & & & & & & & & & & & & & \\
\hline $\mathbf{S}$ & & & & & & & & & & & & & & \\
\hline $\mathbf{T}$ & & & & & & & & & & & & & & \\
\hline $\mathbf{U}$ & & & & & & & & & & & & & & \\
\hline $\mathbf{V}$ & & & & & & & & & & & & & & \\
\hline $\mathbf{W}$ & & & & & & & & & & & & & & \\
\hline $\mathbf{X}$ & & & & & & & & & & & & & & \\
\hline $\mathbf{Y}$ & & & & & & $X$ & & $X$ & & & & & & $X$ \\
\hline $\mathbf{Z}$ & & & & & & & & & & & & & & \\
\hline Skor & 26 & 26 & 23 & 25 & 26 & 25 & 26 & 23 & 26 & 25 & 26 & 26 & 26 & 25 \\
\hline
\end{tabular}

Melalui hasil checklist perilaku di atas, terlihat bahwa ada 6 dari 14 partisipan yang masih melakukan beberapa kesalahan dalam mempraktikkan alfabet A-Z dalam BISINDO, sehingga tidak memperoleh skor sempurna yaitu skor=26. Rata-rata partisipan melakukan kesalahan dalam mempraktikkan huruf F, G, H, K, dan Y. Delapan orang partisipan lainnya berhasil mempraktikkan huruf $\mathrm{A}$ hingga $\mathrm{Z}$ secara keseluruhan dengan tepat. Persentase partisipan yang berhasil mempraktikkan dengan sepenuhnya benar adalah 57,14\%.

Hal yang diukur selanjutnya adalah kemampuan partisipan untuk dapat menyelesaikan 12 pertanyaan yang diberikan dalam waktu antara 4 hingga 7 menit. Kemampuan ini hanya dapat diukur kepada 12 orang partisipan yang memiliki pasangan Teman Tuli. Dalam mengukur hal ini, kelompok melakukan dua kali pengukuran. Yang pertama dilakukan pada sesi Percakapan Pertama, untuk melihat berapa banyak butir item yang dapat ditanyakan Teman Dengar terhadap Teman Tuli dalam kurun waktu 10 menit. Pengukuran yang kedua dilakukan pada sesi Percakapan Kedua, untuk melihat berapa banyak waktu yang dibutuhkan Teman Dengar untuk menanyakan 12 pertanyaan pada Teman Tuli, menggunakan pengetahuan BISINDO. Berikut penjabaran dan komparasi hasil dari tiap-tiap partisipan dalam bentuk tabel:

Tabel 4. Hasil Evaluasi Pengetahuan: Durasi dan Jumlah Pertanyaan

\begin{tabular}{cccccc}
\hline No. & Sesi 1 & Durasi & & & Item \\
& Sesi 2 & Sesi 1 & Sesi 2 \\
\hline 1 & $10^{\prime}$ & 6 & 8 & 12 \\
\hline 2 & 10 & 7 & 6 & 12 \\
\hline 3 & 10 & $7^{\prime}$ & 6 & 12 \\
\hline
\end{tabular}




\begin{tabular}{ccccc}
\hline \multicolumn{5}{c}{ Tidak ada pasangan Teman Tuli } \\
\hline 4 & $10^{\prime}$ & $5^{\prime}$ & 5 & 12 \\
\hline 5 & $10^{\prime}$ & $7^{\prime}$ & 7 & 12 \\
\hline 7 & $10^{\prime}$ & $7^{\prime}$ & 4 & 12 \\
\hline 8 & $10^{\prime}$ & $6^{\prime}$ & 6 & 12 \\
\hline 9 & & Tidak ada pasangan Teman Tuli & \\
\hline 10 & $10^{\prime}$ & $5^{\prime}$ & 7 & 12 \\
\hline 11 & $10^{\prime}$ & $5^{\prime}$ & 5 & 12 \\
\hline 12 & $10^{\prime}$ & $6^{\prime}$ & 7 & 12 \\
\hline 13 & $10^{\prime}$ & $5^{\prime}$ & 6 & 12 \\
\hline 14 & $10^{\prime}$ & $8^{\prime}$ & 4 & \\
\hline
\end{tabular}

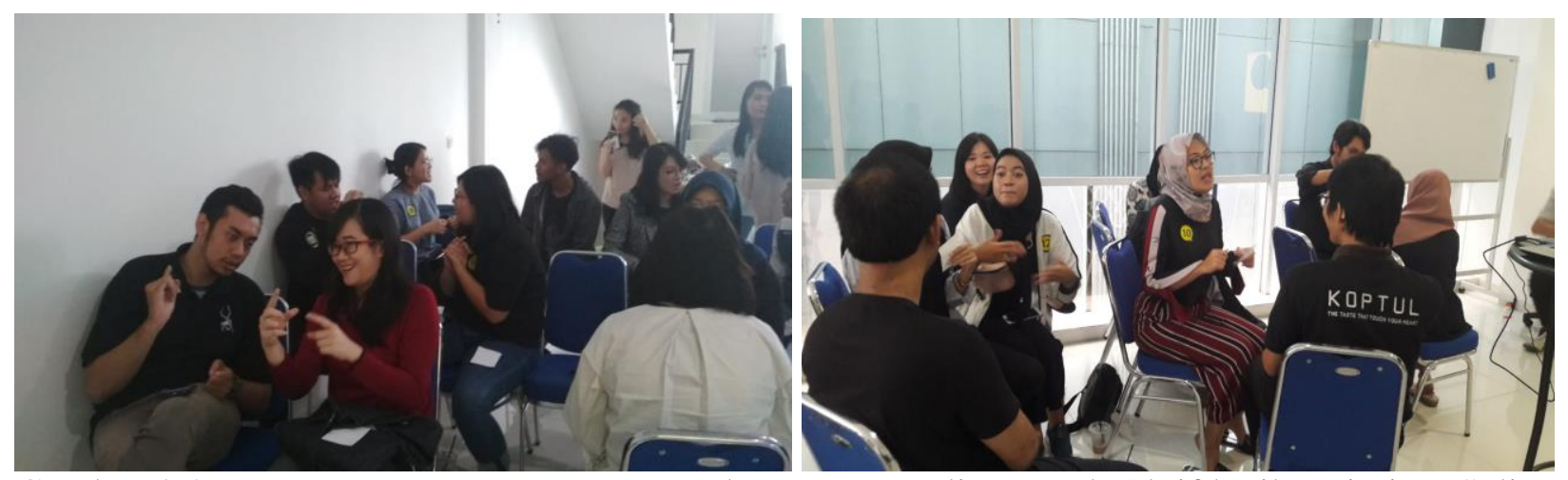

Gambar 4 \& 5. Para Peserta Teman Dengar dan Teman Tuli Tampak Aktif ketika Diminta Saling Mengobrol

\section{KESIMPULAN DAN SARAN}

Para partisipan (Teman Dengar) dapat dikatakan berpartisipasi aktif dan antusias dalam mengikuti intervensi ini. Hal tersebut dilihat dari aktifnya para partisipan saat mengikuti setiap sesi, aktif bertanya dan menjawab pertanyaan. Bahkan, walaupun acara sudah dinyatakan selesai, tidak seluruh Teman Dengar langsung pulang seusai acara. Sebagian besar di antaranya tetap berada di lokasi dan mengobrol lebih jauh dengan para Teman Tuli. Ada pula beberapa Teman Dengar yang bertukar kontak dengan Teman Tuli untuk mempelajari BISINDO lebih lanjut, maupun untuk mengikuti acara-acara lain yang diselenggarakan Teman Tuli nantinya.

Secara keseluruhan, 13 dari 14 partisipan $(92,86 \%)$ merasa puas dengan program intervensi yang telah dilakukan, dan merasakan manfaat dari program intervensi yang diberikan. Sebanyak 9 dari 14 partisipan $(64,29 \%)$ berpendapat bahwa manfaat yang mereka rasakan adalah mempermudah komunikasi/interaksi dengan Teman Tuli, sehingga dapat membantu mewujudkan lingkungan yang lebih inklusif bagi Teman Tuli. Sebanyak 3 dari 14 partisipan (21,43\%) berpendapat bahwa manfaat yang mereka rasakan lebih cenderung ke memperoleh pengalaman yang baru dan memperluas lingkup pergaulan dengan orang-orang yang baru pula. Satu orang partisipan $(7,14 \%)$ mengaku bahwa dengan mengikuti program intervensi ini, ia dapat belajar untuk lebih menghargai orang lain yaitu para Teman Tuli. Sementara 1 partisipan $(7,14 \%)$ mengaku merasa kurang puas pada program intervensi ini, dikarenakan merasa materi masih kurang dan kurang kesempatan untuk bertanya lebih jauh. Setelah ditelaah lebih lanjut, partisipan 
yang mengaku kurang puas ini ternyata datang terlambat sehingga tidak mengikuti sesi intervensi dari awal.

Seluruh partisipan (100\%) mengaku tertarik untuk mempelajari BISINDO lebih lanjut lagi apabila memperoleh kesempatan di waktu yang akan datang. Sebanyak 9 dari 14 partisipan $(64,29 \%)$ menjelaskan bahwa alasan mereka ingin mempelajari BISINDO adalah untuk membantu, mempermudah komunikasi, dan interaksi dengan Teman Tuli nantinya. Sementara lima partisipan lainnya $(35,71 \%)$ menjelaskan bahwa alasan mereka ingin mempelajari BISINDO adalah sebatas ingin memperluas wawasan dan pengetahuan pribadi mereka.

\section{REFERENSI}

Afrianty, D. (2015, July 27). People with disability: locked out of learning? Dipetik April 7 , 2019, from The University of Melbourne: Indonesia at Melbourne: https://indonesiaatmelbourne.unimelb.edu.au

Afrianty, D., \& Soldatic, K. (2016, September 6). Disability inclusive education in Indonesian Islamic education institutions. Dipetik April 7, 2019, from Global Disability Watch: http://globaldisability.org

De Souza, M. F., Araújo, A. M., Sandes, L. F., Freitas, D. A., Soares, W. D., Vianna, R. S., \& De Sousa, Á. A. (2017). Main difficulties and obstacles faced by the deaf community in health access: an integrative literature review. Revista CEFAC, 19(3), 395-405. doi:10.1590/1982-0216201719317116

Kementerian Kesehatan RI. (2014). Situasi penyandang disabilitas. Jakarta: Kementerian Kesehatan RI. Dipetik April 7, 2019, from www.depkes.go.id

Kusters, A. (2017). When transport becomes a destination: deaf spaces and networks on the Mumbai suburban trains. Journal of Cultural Geography, 34(2), 170-193. doi:10.1080/08873631.2017.1305525

Luft, P. (2000). Communication barriers for deaf employees: Need assessment and problemsolving strategies. Work, 14(1), 51-59.

Tuwo, G. A. (2016) Sebutan tuli atau tuna rungu, mana yang lebih tepat? Diakses pada 29 April 2019 dari https://www.liputan6.com/global/read/2654898/sebutan-tuli-atau-tuna-rungumana-yang-lebih-tepat 